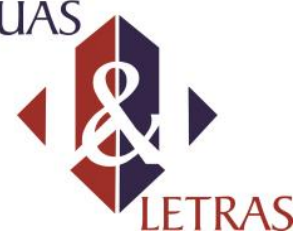

\title{
Um Diálogo ao Sul: Antonio Candido e Ángel Rama
}

\author{
A southernside dialogue:Antonio Candido and Angel Rama
}

José Quintão de Oliveira*

*Universidade de São Paulo, Instituto de Estudos Brasileiros, Rua da Praça do Relógio, Butantã 05508050 - São Paulo, SP - Brasil, e-mail: jqojqo@ yahoo.com.br

RESUMO: A partir de 1960, quando se encontraram pela primeira vez, Antonio Candido e Ángel Rama iniciaram um diálogo intelectual que se prolongou no tempo e marcou profundamente a trajetória dos dois pensadores. Os dois críticos literários se influenciaram reciprocamente e partilharam alguns sonhos e aventuras intelectuais. A divulgação da obra de Rama no Brasil, tanto quanto a circulação dos escritos de Candido no âmbito continental talvez sejam algumas das consequências desse diálogo. Acompanhá-los nesse movimento é o caminho escolhido para melhor compreender o lugar e o papel desses dois pensadores tanto quanto a repercussão e convívio com Rama sobre a práxis crítica do brasileiro.

PALAVRAS CHAVE: Literatura latino-americana; diálogo intelectual; Antonio Candido; Ángel Rama.

ABSTRACT: Since 1960 when first met, Antonio Candido e Angel Rama start a lasting intelectual dialogue wich deeply marked their course. As a result they influenced each other and shared some dreams e intelectual adventures. The continental circulation of their works could be a consequence, among others, of their meeting. Following both of them in their dialogue is the way to better comprehend its consequences on Candido's criticism as far as the place and role of these thinkers.

KEYWORDS: Latin-American literature; intelectual dialogue; Antonio Candido; Angel Rama.

\section{INTRODUÇÃO}

Em 1960, quando iniciava o magistério de Literatura, em Assis, Antonio Candido esteve por uma semana em Montevidéu atendendo a um convite para pronunciar um ciclo de quatro conferências em um curso de verão na Universidade da República. Por essa época Angel Rama, então professor de literatura no ensino médio, se dedicava também à crítica teatral militante no diário Acción; havia retomado há cerca de um ano a direção da página literária do prestigioso semanário Marcha e iniciava suas atividades de editor, organizando Volume 17 Número 38 


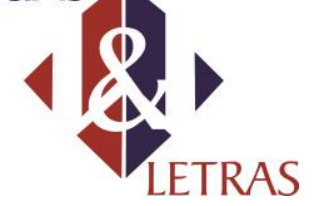

a coleção Letras de Hoy para a editora Alfa. A visita de Candido e a aproximação entre os dois intelectuais foi definitiva para o jovem Rama, marcando-lhe profundamente a vida, estabelecendo muitos dos caminhos que percorreria. Tornaram-se amigos, o que significou para o uruguaio a oportunidade de estabelecer um profícuo diálogo intelectual com o também jovem e bem preparado intelectual brasileiro, autor do recém-lançado Formação da literatura brasileira, então ensinando literatura na recém-fundada Faculdade de Filosofia Ciências e Letras de Assis, no interior de São Paulo.

Esses inícios dos anos sessenta - "anos do questionamento e da fé utópica" como os nomeou a professora Ana Pizarro (2001. p. 245) -, além de marcantes na vida dos dois jovens críticos o são também para a América Latina, que há pouco testemunhara a experiência da revolução cubana; o Brasil passava pelo breve intervalo do governo Jânio Quadros ao qual sucederia o bem-intencionado e conturbado governo de Jango Goulart, que, por sua vez, desaguará no golpe militar e na ditadura de tão tristes lembranças para os brasileiros. Nesse ambiente de efervescência política a envolver tanto o Brasil quanto o restante da América Latina, Ángel Rama já iniciara sua jornada integradora das literaturas latino-americanas, de que era eficaz tribuna a página literária de Marcha.

\section{UM DIÁLOGO CONTINENTAL}

Esse encontro teria muitas consequências nas vidas dos dois: mais tarde Rama seria convidado por Candido a lecionar na USP, como este recorda, destacando o envolvimento do amigo uruguaio em um malogrado sonho latino-americanista com se comprometera o brasileiro:

Em 1973 [Rama] deu um curso breve e memorável na Universidade de São Paulo, além de participar conosco dos trabalhos da revista Argumento, que a ditadura militar cortou no quarto número e que tencionávamos transformar numa publicação de cunho e âmbito latinoamericanos. (CANDIDO, 2001. p. 263).

São memórias do crítico brasileiro, que relata ainda duas outras viagens de Rama a São Paulo:

Em 1980 e 1983 esteve na Universidade Estadual de Campinas em atividade de integração latino-americana, e em cada uma dessas viagens comprava mais livros, abria novos campos de interesse e demonstrava 
conhecimento crescente e profundo a respeito do Brasil. (CANDIDO, 2001. p. 263).

Anteriormente ao primeiro contato com Candido, o uruguaio já estivera brevemente no Brasil, durante os anos 50, que lhe propiciou rápido encontro com o poeta Carlos Drummond de Andrade. Aparentemente, essas três são todas as viagens que Rama fez ao Brasil, em que se encontrou com Antonio Candido. Também tiveram alguns encontros em congressos internacionais, no exterior, e mantiveram uma correspondência significativa, suficiente para cultivar e estreitar a amizade que entre eles se estabelecera desde o primeiro encontro.

Rama se embebeu da visada teórica do colega brasileiro, como já apontou mais de um estudioso, e se interessou especialmente pela literatura do Brasil. O conceito de sistema literário se torna central no seu pensamento, como se pode entrever numa entrevista ocorrida nessa primeira visita, saída no semanário Marcha, em 26 de abril de 1960, em que o uruguaio define, aparentemente, pela primeira vez sistema literário como

a articulação dinâmica de um conjunto de autores e de um público consumidor real que atuam dentro do funcionamento eficaz da vida nacional, com um repertório de temas e delineamentos que asseguram a continuidade regular, em uma palavra, a verdadeira tradição de uma literatura. (RAMA, 2001. p. 69).

A apropriação desse conceito por Ángel Rama significou a sua aplicação ampliadora de que é exemplo o ensaio Meio século de narrativa latino-americana: 19221972, editado em 1973. Ainda um outro exemplo, a aplicação do conceito, em uma forma restritiva, como se dá no ensaio $\mathrm{O}$ poeta no carnaval democrático, publicado postumamente em 1985, no livro As máscaras democráticas do Modernismo, editado pela Fundação Ángel Rama, de Montevidéu. Observe-se que no primeiro caso, Rama opera com a idéia de sistema visando à integração da literatura do Brasil à literatura da América Latina, com visos de romper barreiras impostas pela geografia e pela história. No segundo caso, sistema se aplica a um grupo de poetas específicos do chamado modernismo hispano-americano, que cronologicamente corresponde ao parnasianismo e ao simbolismo brasileiro. Em nenhum dos casos, uma aplicação mecânica.

Desde que se conheceram, Rama se empenhou em divulgar pelo continente a obra do amigo. Por sua iniciativa se editaram alguns ensaios do brasileiro pelos países da América Latina, onde este alcançou repercussão e conquistou leitores. Em consequência, 
ampliou-se a interlocução de Antonio Candido com o Continente, tornando-o o crítico literário brasileiro de mais ampla circulação na região. Inicia-se dessa maneira um diálogo que, no futuro, envolverá ainda professores e intelectuais como Beatriz Sarlo, Raúl Antelo, Jorge Ruedas de la Serna - último orientando de Candido, no doutorado -, para citar apenas três.

O contato mais sistemático desse brasileiro com a literatura hispano-americana data do início dos anos cinquenta e só faz se tornar mais estreito com o passar dos anos. Fato bastante perceptível, por exemplo, no livro Recortes, de 1992, em que se patenteia a centralidade da América Latina, a solidariedade a Cuba e o sentimento de amizade por Ángel Rama. Pelo menos cinco ensaios deste livro tematizam o que pode ser dito a latinoamericanidade do escritor, incontáveis outras vezes manifesta, em entrevistas, textos escritos, etc..

No livro A educação pela noite (2006), Candido observa que falar de literatura latino-americana a um brasileiro significa ser entendido como se falando dos países de língua espanhola, em sua rica e desafiante multiplicidade. Apenas em um segundo movimento, reflexivo, lhe ocorrerá que o termo inclui também o Brasil. Outro tanto ocorre com o hispânico, que também exclui o Brasil da sua idéia de América Latina. Assim, para os latino-americanos - falem espanhol ou português -, no mapa literário da América ocorre um vazio, correspondente ao espaço ocupado pelo Brasil nos mapas geográficos. A interlocução intelectual dos escritores brasileiros esteve sempre voltada para a Europa, particularmente a França (a princípio pela via de Portugal), mais amplamente, para a Europa; depois para os Estados Unidos. Não obstante o território, a cultura e a história comuns dos Pampas, salvo para algum utopista do latino-americanismo, os Andes sempre foram um obstáculo grande demais para ser transposto pelos brasileiros.

No mesmo ensaio, acima referido, escrito para uma obra coletiva publicada pela editora Siglo Veintiuno sob o patrocínio da Unesco, Candido traça um paralelo entre as duas realidades, visando mostrar as inúmeras aproximações existentes entre os falantes desta nossa "língua do ão", na expressão de Mário de Andrade (1987) no poema Noturno de Belo Horizonte, e aqueles que herdaram a língua de Cervantes. Talvez o suficiente para se falar em uma literatura latino-americana? Não se ousa responder à questão, registra-se, no entanto, que a resposta de Rama era irrecorrivelmente positiva, em que pesem as dúvidas que sua condição de pensador lhe impunha.

Volume 17

Número 38 


\section{UM ENCONTRO PRODUTIVO}

Ángel Rama bem aproveitou a oportunidade do contato direto com Candido, que soube ampliar tanto em direção a outros textos do crítico brasileiro quanto para a literatura brasileira num sentido mais amplo, seja através dos livros que este lhe franqueava, ou buscando adquirir diretamente a maior quantidade possível de obras que devorava em leituras rapidíssimas que nada perdiam de qualidade crítica. É ainda Candido a lembrar que

Pelo Brasil ele tinha um interesse pouco frequente entre intelectuais latino-americanos de fala espanhola e chegou a conhecer relativamente bem a nossa cultura e em especial nossa literatura, com a capacidade quase incrível de leitura e a rapidez de percepção que caracterizava a sua inteligência luminosa. (CANDIDO, 2001. p. 263).

Quando da instalação da ditadura militar no Uruguai, exilado na Venezuela, tornou realidade um antigo sonho latino-americanista e organizou a Biblioteca de Ayacucho, ambiciosa empreitada que visava à construção de uma coleção que representasse amplamente a literatura das Américas e "que se tornou uma das mais notáveis empresas de conhecimento e fraternidade continental da literatura e do pensamento. Inclusive porque foi a primeira vez que o Brasil apareceu num projeto deste tipo em proporção adequada." (CANDIDO, 2001. p. 263). São palavras de Antonio Candido, que se responsabilizou pela parte relativa ao Brasil na Biblioteca de Ayacucho. Além disso, organizou os volumes Memórias de um sargento de milícias, de Manuel Antônio de Almeida, para o qual redigiu um prólogo e as notas ao texto; e também aquele dedicado a Sílvio Romero, para o qual selecionou os textos e redigiu a apresentação.

O volume 162 desta coleção, intitulado Crítica radical, constitui a primeira obra integralmente dedicada à divulgação mais ampla e sistemática da obra de Antonio Candido em espanhol, saiu em 1991, com tradução e notas de Mágara Russoto e um prólogo de Agustín Martinez. Anteriormente, além dos ensaios esparsos já referidos, em 1968, saíra na Venezuela um pequeno opúsculo intitulado Introducción a la literatura de Brasil, reeditado em 1981 em Cuba. Depois do volume da Biblioteca de Ayacucho, impregnados pelo espírito dessa coleção, circularam no México os volumes Ensayos e comentários, numa coedição da Fondo de Cultura Econômica com a editora da Unicamp, em 1995; e cinco anos mais tarde, Estruendo y liberación (organizado por Jorge Ruedas de la Serna e Volume 17 Número 38 


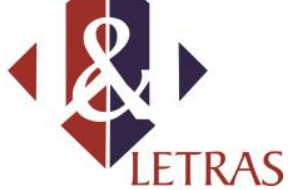

Antônio Arnoni Prado), editado pela Siglo Veintiuno. O lançamento desse livro suscitou a organização no México de um seminário reunindo professores e intelectuaislocais e brasileiros e com o objetivo de analisar

a relação e o deslinde das fronteiras entre história literatura e sociedade; a articulação entre literatura nacional e literatura latino-americana; o conceito de sitema literário e sua importância para o estudo da recepção literária e a formação do cânon; [...] a importância da filologia para o resgate de nosso patrimônio literário e a natureza estética irrenunciável da obra literária. (RUEDAS DE LA SERNA, 2003. 2. orelha).

Entre outros temas; como se percebe, uma pauta totalmente sintonizada com as reflexões o professor e pensador brasileiro. O seminário, por sua vez, resultou no volume bilíngue (português e castelhano) Antonio Candido: história e literatura, organizado pelo mesmo Ruedas de la Serna, editado no Brasil com o objetivo de circular no âmbito continental.

Certamente, apesar de todos os problemas e dificuldades, por demais conhecidos, o encontro entre Candido e Rama foi frutífero para o intelectual uruguaio e para o brasileiro. Mais que isso, porém, foi extremamente produtivo para os estudos literários na fatia latina das Américas. Tão produtiva que repercutiu na Universidade, extrapolando as fronteiras ibero-americanas, chegando mesmo às terras ao norte do Rio Grande, onde em 2001 Raúl Antelo organizou para a Universidade de Pittsburgh o volume Antonio Candido y los estudios latinoamericanos, que reuniu inúmeros ensaios de autoria de estudiosos de diversas nacionalidades sobre a obra do autor de Formação da literatura brasileira.

\section{SISTEMA E COMARCA}

Retornando ao conceito de sistema literário, deve ser anotado - e enfatizado -, que a sua apropriação por parte de Ángel Rama não significou em nenhum momento uma assimilação passiva. Muito ao contrário, como já se anotou, revelando-se um mestre no sentido poundiano, o crítico uruguaio tomou o conceito elaborado pelo brasileiro e ao aplicá-lo deu-lhe uma dimensão impensada pelo seu criador, como se percebe no já citado Meio século de narrativa latino-americana: 1922-1972. Agregou-lhe a idéia de Comarca definida como uma continuidade de cultura, de costumes e de populações capaz de extravasar as fronteiras nacionais, unindo países ou parcelas de países diversos, como se dá, 
por exemplo, nos Pampas (como já se referiu aqui), - e construiu uma análise integradora da literatura latino-americana, começando a tornar real aquela unidade com que, no início do século 20, já sonhava o brasileiro Manuel Bonfim.

Parece ocorrer na trajetória dos dois críticos e pensadores uma espécie de intersecção, geradora de alguma forma de contiguidade intelectual e mesmo ideológica, cuja consequência principal seria a geração de uma trajetória paralela e complementar que os manteria ligados. Um dos frutos dessa contiguidade pode ser vislumbrado no que pode ser dito uma orgulhosa consciência do próprio ser no mundo. Isso redunda numa espécie de capacidade de ver-se e sentir-se como parte do mundo, percebendo a própria condição de pensadores a partir de um lugar específico, nunca periféricos ou subalternos. É realmente necessário se observar que a partir da América Latina, mais particularmente de São Paulo e de Montevidéu, dois intelectuais se mostraram capazes de efetuar uma intensa e profícua troca de experiências e de idéias, constituindo uma cultura e um pensamento crítico que extravasam de muito os acanhados limites que sua condição de pensadores a partir da periferia lhes impõe. Talvez, pela primeira vez, se possa vislumbrar a perspectiva de uma produção metódica de saber capaz de abarcar a totalidade do seu universo gerador e a partir desse fertilizar outros pensamentos e provocar respostas que ampliam e repercutem as vozes latino-americanas desses mestres e daqueles que prosseguem nos caminhos que traçaram e buscam atingir as ambiciosas metas que vislumbraram.

Candido e Rama souberam evitar com galhardia a armadilha que sempre se apresenta àqueles que ao pensar a unidade escamoteiam a diversidade. Esse risco de dizer ibero-americanos em substituição a brasileiro ou uruguaio; de dizer brasileiro em lugar de dizer mineiro ou paulista; ou, no percurso inverso, dizer o particular quando cabia buscar o geral. Parece que essa capacidade se expressou nesses dois pensadores a partir da rara competência de transitar entre a análise monográfica e as grandes sínteses, revelando um pensamento e uma aptidão à integração intelectual que transita do geral ao particular e deste àquele sem perder pelo caminho a nuanças diferenciadoras. Movimentar-se da análise da obra de Machado de Assis ou de Jorge Luís Borges à percepção de um sistema literário que se constitui num espaço e num tempo e se definem por peculiaridades internas e por tramas enlaces com o mundo exterior, sem perder nunca de vista que esta generalização só existe e se justifica mediante a valorização das individualidades que a constituem e concretizam. 


\section{CONCLUINDO OS TERMOS}

Pensado inicialmente a partir do objetivo de partir de Ángel Rama para abarcar a recepção da obra de Candido pela crítica literária hispano-americana, este ensaio terminou por centralizar-se no diálogo intelectual entre os dois pensadores, pela singela razão de se constatar que, dada a amplitude da repercussão do pensamento do primeiro e da atividade intelectual do segundo, corria-se o risco de terminar por se elaborar uma lista de nomes de intelectuais e professores. Lista das mais nobres, tantos seriam os nomes a ilustrá-la, mas, certamente, pouco eficaz como prática de estudo.

Acompanhar os passos de Rama é observar a trajetória do professor universitário, crítico literário, debatedor e conferencista, editor, animador cultural e acima de tudo, a trajetória do intelectual empenhado na construção de uma utopia que se concretiza em empreendimentos que lentamente transformam a realidade e abrem às gerações que sucedem a perspectiva de sonhar mais amplo, de um ponto mais elevado, os sonhos transformadores que soube com seu trabalho incutir nesses outros. Não signifique isso um balanço entusiástico. Longe disso. Como observou o próprio Rama, a construção de uma América Latina é um projeto vanguardeiro. Hoje, como no seu tempo, aguarda ainda por realização. O que se deve registrar é que as sementes que o grande crítico semeou não se esterilizaram; não morreram. Há algo de Rama no crescimento do ensino da língua espanhola e da cultura hispânica em nossas universidades. Assim como há algo de Rama nos vacilantes e ainda meio canhestros passos que a América do Sul tem dada na tentativa de constituir ao menos em um mercado capitalista unificado. Muitos dos políticos e intelectuais que, do lado brasileiro, impulsionaram essa aproximação estavam presentes às reuniões com Rama ocorridas a partir de 1973, já referidas aqui, conforme o relato de Antonio Candido.

Para encerrar seria interessante, ainda, observar que Antonio Candido sempre se apresentou como crítico literário, sempre falando orgulhosamente do tempo em que ocupava a posição de crítico titular nos rodapés dos diários paulistas. Nessa condição

produziu toda sua obra na sua parte voltada à literatura. Por indústria de Ángel Rama, no entanto, terminou sendo assimilado pelos seus pares latino-americanos como um teórico da literatura. Assim, as ironias da recepção fazem com que o teórico brasileiro de maior 


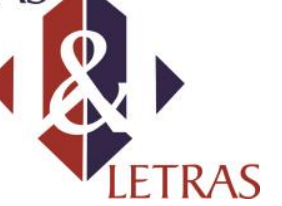

projeção além-fronteiras seja exatamente um intelectual e professor que sempre se preocupou em pensar a literatura a partir da posição de leitor especializado, afirmando peremptoriamente sua exclusiva condição de crítico literário.

\section{REFERÊNCIAS}

ANDRADE, Mário de. Poesias completas. Ed. crítica de Diléa Zanotto Manfio. Belo Horizonte: Itatiaia, 1987.

CANDIDO, Antonio. A educação pela noite. 5. ed. rev. pelo autor. Rio de Janeiro: Ouro sobre Azul, 2006.

. Uma visão latino-americana. In: CHIAPPINI, Lígia; AGUIAR, Flávio Wolf de.

Literatura e história na América Latina. São Paulo: Edusp, 2001. p. 263-270.

PIZARRO, Ana. Ángel Rama: a lição intelectual latino-americana. In: CHIAPPINI, Ligia; AGUIAR, Flávio Wolf de. (org.). Literatura e história na América Latina. São Paulo: Edusp, 2001. p. 243-253.

RAMA, Ángel. Una entrevista olvidada de Ángel Rama a Antonio Candido. In: ANTELO, Raúl. (ed.). Antonio Candido y los estudios latinoamericanos. Pittsburg: Instituto Internacional de Literatura Iberoamericana/Universidad de Pittsburg, 2001. p. 68-70.

RUEDAS DE LA SERNA, Jorge. (org.) Antonio Candido: história e literatura. Campinas: Ed. da Unicamp, 2003.

Data de recebimento: $27 / 07 / 2016$

Data de aprovação: 28/11/201 